\title{
Conservação e valorização do patrimônio da moda. 0 papel social da pós-história ${ }^{1}$
}

\section{DANIELA CALANCA}

\section{Resumo}

A moda e sua história constituem elementos fundamentais do patrimônio cultural de uma nação, de um povo. "Fashion and Heritage" há alguns anos significa projetos de pesquisa institucional e de estudo. Em particular, no que se refere ao âmbito italiano, Itália e moda tornaram-se, nas últimas décadas, duas palavras-chaves inseparáveis: a imagem contemporânea da Itália está profundamente marcada pela indústria da moda e vice-versa. A moda italiana, na verdade, é um ícone cultural, um elemento de estilo e de bem-estar, uma referência estética e base da qualidade de vida em que a história desempenha um papel fundamental.

Palavras-chave:

Moda, patrimônio cultural, história pós-social 


\section{Conservation and enhancement of fashion heritage. The role of post social history}

\section{DANIELA CALANCA}

\section{Abstract}

Fashion and its history form a fundamental tile of the Cultural Heritage of a nation and a community. Over recent years "Fashion and Heritage" has meant institutional research project and studies. Particularly, in terms of Italian context, in the last decades, Italy and Fashion, are two keywords that can't be separated: the contemporary image of Italy is deeply signed from fashion industry and vice versa.

Keywords: Fashion, cultural heritage, postsocial history Italian fashion is indeed a cultural icon, an element of style and wellbeing, an aesthetic and establishing reference for the Quality of Life, in which history play a leading role. 
$E_{m}$ particular, "Fashion and Heritage" é a relação entre moda e patrimônio que se configura, historicamente, como ponto de encontro social entre cultura, economia, arte e política (CALANCA, 2008). Neste sentido, do ponto de vista econômico, no âmbito italiano e internacional, tal relação já produziu resultados notáveis. Inspiradas pela tradição, mas de olho no futuro, muitas empresas italianas e europeias alcançaram grande sucesso hoje (CALANCA, 2012).

No entanto, "Fashion and Heritage" há alguns anos tem desenvolvido também produtos culturais institucionais, ou seja, projetos de pesquisa e de estudo a partir dos quais se considera a moda e sua história como elementos-chave do patrimônio cultural de uma nação, de um povo (CALANCA, 2011 e 2013). Em particular, no âmbito italiano, Itália e moda, nas duas últimas décadas, são duas palavras-chaves inseparáveis: a imagem contemporânea da Itália está profundamente marcada pela indústria da moda e vice-versa. A moda italiana, na verdade, é um ícone cultural, um elemento de estilo e de bem estar, referência estética e base da qualidade de vida, em que a história desempenha um papel primordial, de base. Portanto, a história da moda, seus estudos e suas culturas históricas sociais constituem parte fundamental do "Sistema da Moda italiano", do Made in Italy (CALANCA 2013; GNOLI, 2005 e 2012; MERLO, 2003; PARIS, 2006).

O Made in Italy, por sua vez, é um fenômeno multidimensional e está enraizado na inovação do produto e na promoção da imagem. Teve o seu início nos anos 6o do século passado. Mas qual é a cultura, quais as culturas, sobre o que se apoia o Made in Italy?A cultura de referência é a da experimentação, dentro da lógica internacional do consumo. Nesta perspectiva o Made in Italy possui profundas relações com as mudanças da sociedade, especialmente a partir da década de 80 , quando foram os estilos de vida a influenciarem as práticas estéticas. 
Na verdade, as marcas não só cresceram simbolicamente por inspiração do estilista, mas em razão do estilo de vida que caracterizava uma determinada faixa da população (BALDOLI e MORRIS, 2006; MONTAMAGGI e SEVERINO, 2007; OKONWO, 2007; VOLONTE, 2003).

Em particular, a indústria da moda italiana está organizada ainda hoje em um conjunto de centros especializados, a maioria localizada no centro-norte, que tentam mesclar a tradição artesanal com a adoção de soluções técnicas e organizacionais avançadas. Os principais centros são: Belluno, na produção de óculos; Biella, na indústria têxtil; Carpi e Treviso, na produção de malhas; Mantova na produção de meias; Vicenza e Empoli, no setor de peles; Grumello, na produção de botões; Como, na de seda; Prato, na de lã; Forlì e Cesena, no setor de calçado. Em Biella se encontram algumas das mais importantes empresas de lã e confecções, como Cerruti e Zegna, enquanto que dos curtumes toscanos provém produtos de empresas tradicionais, como Ferragamo, Gucci e Prada.

Além disso, atualmente, os produtos do "Sistema de Moda italiano" tem uma notável capacidade de penetrar especialmente no território europeu: a Europa é o principal mercado deste sistema de moda e, em geral, as empresas italianas representam um quarto do faturamento total da indústria têxtil na Europa.

Ao lado deste dinâmico entrelaçamento entre produção e consumo, local e global, o setor da moda na Itália está expandindo a sua dimensão institucional, como registra a crescente influência, também internacional, por exemplo, da Câmara Nacional de Moda Italiana, associação que foi fundada em 1958, para regular, coordenar e promover o desenvolvimento da moda italiana, tanto na Itália quanto no exterior. A Câmara, que tem sede em Milão, estipulou várias alianças com outras grandes capitais da moda e instituições internacionais, especialmente com Paris e Nova York. A propósito, por exemplo, remonta ao ano de 200o, o Protocolo ítalo-francês com o qual se expressa a grande determinação da Câmara Nacional de Moda Italiana e da Federation Française de la Couture de conduzir uma política comum, a fim de desenvolver e difundir produtos de luxo em áreas fora da Europa.

Ao mesmo tempo, a imagem da Itália no exterior está hoje associada a um cenário rico em arte e natureza: um cenário marcado pela ideia de "viver bem", de "qualidade de vida". Deste "viver bem", desta "qualidade de vida" a moda e o estilo italiano, considerados frutos de um passado clássico e atemporal desde Roma até o Renascimento, constituem componentes 
centrais. Para documentar o prestígio do estilo italiano, podemos lembrar que, em 2003, o Fashion Institute of Technology, em Nova York, dedicou-lhe uma importante exposição, promovida por Valerie Steele, um dos estudiosos mais influentes da moda internacional. Ao recuperar as origens do estilo contemporâneo italiano, de Emilio Pucci a Versace, de Ferragamo a Walter Albini, a exposição fez com que ele se tornasse sinônimo de qualidade, uma guia da moda e do que vai além dela, renovando fortes tradições em um campo no qual artesanato e arte se entrelaçam (STEELE, 2003).

II. A partir dessas considerações, portanto, as mais recentes tendências historiográficas italianas e europeias identificam a relação moda e patrimônio cultural como um dos pontos essenciais da pesquisa de hoje. O atual "Sistema de Moda italiano" é baseado na tradição humanista do Renascimento e cruza caminhos de diferentes artes, em particular, figurativas, fotográficas, design e artesanato (MONTEMAGGI e SEVERINO, 2007). Mas também se baseia em uma organização específica de produção, promoção e consumo.

A correlação entre a produção de têxteis e vestuário, entre confecções e design de moda, deu origem ao Italian Style, uma marca de excelência conhecida em todo o mundo, a ponto de ser considerado como patrimônio social. Patrimônio esse que pode ser definido como um paradigma conceitual, teórico e operacional que permite desenvolver pesquisas multidisciplinares no âmbito da história social, examinar realidades concretas, condições de vida, movimentos e história cultural, investigar mentalidades, comportamentos, representações, entre continuidade e mudança. Pesquisas multidisciplinares, portanto, que contemplam, simultaneamente, a confluência de vários fatores, como reflexo do articulado entrelaçamento entre os fenômenos sociais, econômicos, políticos, culturais, costumes, a preservação deles e a transmissão histórica.

Em síntese, a formulação do paradigma conceitual da herança social é acompanhada por uma ampliação da pesquisa histórica, pela noção de patrimônio cultural imaterial, conforme definido na Convenção para a Salvaguarda do Patrimônio Cultural Imaterial, proclamada em Paris pela Organização das Nações Unidas para a Educação, a Ciência e a Cultura (UNESCO) em 2003, em vigor definitivamente em 2006: "Por patrimônio cultural imaterial se entende: as práticas, representações, expressões, conhecimentos, know-how - bem como os instrumentos, objetos, artefatos e espaços culturais que lhes estão associados - que as comunidades, os grupos e em alguns casos, os 
indivíduos reconhecem como parte do seu patrimônio cultural. Este patrimônio cultural imaterial, transmitido de geração em geração, é constantemente recriado pelas comunidades e pelos grupos como resposta ao ambiente que os circunda, à interação com a natureza e à história, dando-lhes um sentimento de identidade e continuidade e promovendo assim o respeito pela diversidade cultural e pela criatividade humana". Uma herança que por sinal é definida nas seguintes áreas: "a) tradições e expressões orais, tendo o idioma como veículo do patrimônio cultural imaterial, b) artes cênicas, c) tradições sociais, rituais e festas; d) conhecimentos e práticas sobre a natureza e o universo, e) artesanato tradicional" (UNESCO).

Em razão das ligações científicas e epistemológicas que se configuram entre o patrimônio imaterial a transmissão histórica do que constitui a identidade e a preservação de uma comunidade, a ênfase da reflexão se move dos fatos que constituem a história e as histórias da moda para o plano das lembranças, da memória. Mas, resumidamente, entre nova história e memória, se delineia a história pós-social, uma orientação historiografia, nascida no âmbito anglo-saxão, ainda desconhecida na Itália. Uma abordagem historiográfica que, apesar de ainda não se apresentar como uma verdadeira "escola", pode contribuir para o desenvolvimento de pesquisas científicas multidisciplinares. (CABRERA, 2004; CALANCA, 2011).

Nesse sentido, a partir da forte necessidade de prosseguir para além do debate entre materialismo e idealismo, objetividade e subjetividade, no plano historiográfico internacional estamos assistindo uma significativa reformulação da disciplina histórica como tal. Trata-se de um repensamento que, causado pela crise da modernidade, resulta na produção de uma nova interpretação teórica da sociedade. Essa interpretação tem uma lógica causal diferente daquela desenvolvida pelos historiadores cerca de vinte anos atrás (ibid.).

Na verdade, a história tradicional baseou-se na subjetividade dos agentes históricos e era considerada racional e autônoma; para os historiadores sociais a subjetividade e a cultura não são produtos racionais, mas representações ou expressões do contexto social em que as causas da ação se fundaram. Assim, dentro desta perspectiva, a análise teve o seu início a partir das estruturas sócio-econômicas para atingir as práticas culturais.

No entanto, nas últimas décadas, desenvolveu-se um paradigma teórico que se opõe tanto à história idealista quanto à materialista. Partindo da premissa - semelhante ao da nova história cultural - segundo a qual a realidade social está sempre 
inserida na consciência dos indivíduos por meio da sua conceituação, os novos historiadores argumentam que o conjunto das categorias mediante as quais os indivíduos se apoderam do significado e organizam a realidade social não consiste nem no reflexo, nem na expressão daquela realidade, mas se configura em um âmbito social específico, com sua própria lógica.

A partir disso, consideram as categorias como uma complexa rede de relações, na qual a natureza não é considerada nem objetiva nem subjetiva, mas fruto de um fenômeno histórico específico, dotada de regras de funcionamento e de mudança. Tais categorias, portanto, não constituem um simples meio para transmitir significados da realidade, mas parte ativa no processo de construção daqueles significados.

Dessa forma, são as práticas e não as estruturas que representam o ponto de partida para a análise histórica social, do momento que as práticas são consideradas, nessa ótica, o espaço no qual se desenvolve o entrelaçamento significativo entre coerção social e iniciativa individual. A ação humana pode ser explicada a partir dos significados que os agentes atribuem ao contexto social. São as práticas, enfim, e não a estrutura, objetivamente no sentido marxista, que constituem o ponto de partida da análise.

O que os novos historiadores procuram oferecer, definitivamente, é um novo paradigma historiográfico, aplicando, substancialmente, entre outros pontos, o conceito de imaginário social, como definido por C. Taylor (2004), isto é: as maneiras pelas quais as pessoas imaginam sua existência, as formas pelas quais as relações sociais se estruturam. Em particular, se refere à maneira pela qual as pessoas comuns imaginam o seu próprio contexto social, que muitas vezes não se materializa em formulações teóricas, mas é transmitido por meio de imagens, histórias e lendas. Além disso, como acontece na maioria dos casos, a teoria é normalmente riqueza de uma pequena minoria, enquanto que o aspecto interessante do imaginário social é compartilhado por grandes grupos de pessoas, se não por toda a sociedade. Isso porque o imaginário social é o conhecimento comum, que torna possível práticas comuns e um sentido de legitimidade amplamente compartilhado. O imaginário social se estende para além do saber e dá sentido as nossas práticas específicas (Ibid.).

Assim, é a importância atribuída a tal entendimento não estruturado e não articulado que autoriza reconhecer, entre outras coisas, a possibilidade de discutir de forma científica, do ponto de vista da pesquisa histórica, a futura memória, de que 
modo as ideias, a mentalidade e os costumes constituem parte na formação, transformação e transmissão da identidade de uma comunidade, de um grupo, constituindo o patrimônio, o seu imaginário. Nasce, assim, a ideia de moda e de suas modas.

\section{Referências}

ANHEIER, Helmut, ISAR, Yudhishthir Raj (eds.). Heritage, Memory \& Identity, London: Sages Publications, 2011.

AUDRERIE, Dominique. La notion et la protection du patrimoine, Paris: PUF, 1997.

BALDOLI, Claudia, MORRIS, Jonathan (eds.). Made in Italy. Consumi e identità collettive nel Secondo Dopoguerra, "Memoria e Ricerca", Milano: Franco Angeli, n. 23/2006.

BELFANTI, Carlo Marco, e GIUSBERTI, Fabio (eds.). La moda. Storia d'Italia, Annali 19, Torino: Einaudi, 2003.

CABRERA, Miguel A. Postsocial History. An introduction. United States of America, Lanham, 2004.

CALANCA, Daniela. Historia social da moda. São Paulo: Senac, 2008.

. Italians posing between public and private. Theories and practices of Social Heritage, "Almatourism. Journal of Tourism, Culture and Territorial Development", Vol. 2, n. 3, 2011 (http://almatourism.unibo.it/).

. Italian Fashion History and Cultural Heritage: Data for a Tourist Guide, "Almatourism. Journal of Tourism, Culture and Territorial Development". Università di Bologna, Vol. 3, n. 5, 2012 (http://almatourism.unibo.it/)

. Storia sociale della moda contemporanea, Bologna: Bononia Uniersity Press, 2013 (in stampa).

COLAIACOMO, Paola (ed.). Fatto in Italia. La cultura del made in Italy (1960-200o), Roma: Meltemi, 2006.

CORBELLINI, Erica, SAVIOLO, Stefania. La scommessa del Made in Italy e il futuro della moda Italiana, Milano: ETAS, 2004.

FONTANA, Franco, CAROLI, Matteo. L'industria della moda in Italia, Roma: Rirea, 2004.

FORTUNATI, Leopoldina, DANESE, Elda. Il Made in Italy, Roma: Meltemi, 2005.

GNOLI, Sofia. Un secolo di moda italiana 1900-200o, Roma: Meltemi, 2005.

Moda. Dalla nascita della haute couture a oggi. Roma: Carocci, 2012.

MERLO, Elisabetta. Moda italiana: storia di un'industria 
dall'Ottocento fino a oggi. Venezia: Marsilio, 2003.

MONTEMAGGI, Marco, SEVERINO, Fabio. Heritage marketing. La storia dell'impresa italiana come vantaggio competitivo, Milano: Franco Angeli, 2007.

OKONKWO, Uche. Luxury Fashion Branding: Trends, Tactis, Techniques. United Kingdom: Palgrave McMillan, 2007.

PARIS, Ivan. Oggetti cuciti, Milano: Franco Angeli, 2006.

SASSATELLI, Roberta. Consumo, cultura e società, Bologna: il Mulino, 2004.

STEELE, Valerie. Fashion. Italian Style. New Haven: Yale University Press, 2003.

TAYLOR, Charles. (2004), Gli immaginari sociali moderni, Roma: Meltemi, 2004.

TESTA, Salvatore (2003), La specificità della filiera italiana della moda, in Belfanti e Giusberti (eds.).

TUNGATE, Mark. Fashion Brands: branding style from Armani to Zara. London: Kogan Page Publishers, 2008.

VOLONTE', Paolo (ed.). La creatività diffusa. Culture e mestieri della moda oggi. Milano: Franco Angeli, 2003.

WHITE, Nicola. Reconstructing Italian Fashion. America and the Development of the Italian Fashion Industry. Oxford: Berg, 200o.

\section{NOTAS \\ 1. Tradução: Angélica Maria Ayres da Silva}

Recebido em: 24/o7/13

Aceito em: 24/08/13

\section{DANIELA CALANCA}

daniela.calanca@unibo.it

Professora de história da indumentária e da moda na área de História

Social da Universidade de Bolonha. Dedica-se também à Antropoogia

Filosófica e política na Idade Antiga, Média e Moderna. Autora de

A história social da moda (Ed. Senac, 2008). 